\title{
Magnetic Fields of Devices during Electric Vehicle Charging: A Slovak Case Study
}

\author{
Iveta Marková $^{1, *}$, Milan Oravec ${ }^{2}$, Linda Makovická Osvaldová $^{1} \oplus$, Eva Sventeková ${ }^{3}$ and Daniel Jurč $^{2}$ \\ 1 Department of Fire Engineering, Faculty of Security Engineering, University of Žilina, Univerzitná 1, \\ 01026 Žilina, Slovakia; linda.makovicka@fbi.uniza.sk \\ 2 Department of Safety and Quality of Production, Faculty of Mechanical Engineering, \\ Technical University of Košice, Letná 1/9, 04200 Košice, Slovakia; milan.oravec@tuke.sk (M.O.); \\ daniel.jurc@student.tuke.sk (D.J.) \\ 3 Department of Crisis Management, Faculty of Security Engineering, University of Žilina, Univerzitná 1, \\ 01026 Žilina, Slovakia; eva.sventekova@fbi.uniza.sk \\ * Correspondence: iveta.markova@fbi.uniza.sk; Tel.: +421-041-513-6799
}

Citation: Marková, I.; Oravec, M.; Osvaldová, L.M.; Sventeková, E.; Jurč, D. Magnetic Fields of Devices during Electric Vehicle Charging: A Slovak Case Study. Symmetry 2021, 13, 1979. https://doi.org/10.3390/ sym13111979

Academic Editors: Deming Lei and Raúl Baños Navarro

Received: 18 August 2021

Accepted: 12 October 2021

Published: 20 October 2021

Publisher's Note: MDPI stays neutral with regard to jurisdictional claims in published maps and institutional affiliations.

Copyright: (c) 2021 by the authors. Licensee MDPI, Basel, Switzerland. This article is an open access article distributed under the terms and conditions of the Creative Commons Attribution (CC BY) license (https:/ / creativecommons.org/licenses/by/ $4.0 /)$.

\begin{abstract}
The aim of this contribution is to identify and quantify the magnetic field parameter (MP) devices for charging electric vehicles (EVs). An EV is a mobile device. The EV remains a mobile device even when it is charging in a fixed charging stand. ICNIRP and SBM standards apply to stable devices. A magnetic field (MF) creates local gradient fields that change cyclically over time near the charging stations. The rotating vector MF is a specific parameter. An MF is evaluated by its strength and spatial changes. The triaxial fluxgate magnetometer VEMA-041 was used for the measurements. The MF was observed in the frequency range of $0-250 \mathrm{~Hz}$, and the magnetic induction density was from T $2 \times 10^{-9} \mathrm{~T}$ to $2 \times 10^{-5} \mathrm{~T}$, with a sensitivity of $1.7 \mathrm{nT}$. The MF analysis was performed within the time and frequency range. The rotating vector MF was identified the measurement points. Measurements were realized for the charge under the following parameters: cables, $600 \mathrm{~A}$; transformer, $250 \mathrm{kVA}$ (22 kV/400 V); a cab-fixed charging stand, and an AC/DC charger in the EV. EV charging was performed with $6.6 \mathrm{~kW}$ of power and 43-kW fast charging. The measured results were satisfactory, according to the ICNIRP and SBM 2015 standard. The values measured at a distance of $1 \mathrm{~m}$ from the wall of the transformer were $B_{R M S}<2 \mu \mathrm{T}$. $B_{R M S}$ values $<3 \mu \mathrm{T}$ were measured in the space of the cable's entry into the distribution box. EV values should not be assessed under this regulation. However, an EV is a mobile device. In the selected EV sample (a first-generation Nissan Leaf), a frequency of $10 \mathrm{~Hz}$ and its multiples were detected during charging. The frequencies were generated in an AC/DC charger in the EV. These frequencies reached $B_{R M S}<0.2 \mu \mathrm{T}$ in the driver's footwell. The maximum value of the MF rotating vector was $B_{\text {total }}<0.3 \mu \mathrm{T}$ and was directed to the crew area of the EV. The AC/DC charger generated $B_{R M S}=0.95 \mu$ Tin the driver's footwell. It is necessary to look for new tools for evaluating MFs for EVs, such as the standards used for stable sources today. These standards should be based on dosimetric principles.
\end{abstract}

Keywords: magnetic field; magnetic field source; charging stands; AC/DC charger in electric vehicle; fluxgate magnetometer; rotating magnetic field vector

\section{Introduction}

The development of electric vehicles entails new risks related to the existence of MFs. Europe has experienced the development of recommendations, special guidelines, and standards for assessing the impact of EMFs with various frequency sources, including ELF sources, since 1995 [1-9]. The magnetic field emitted by the source is a specific type of field. The emitted MF's description using cyclic symmetric functions in both the time and frequency domains is now the basis of the ICNIRP recommendations. Standards in the Slovak Republic are taken from these recommendations. 
The ICNIRP's reference levels for static magnetic fields (the magnetic flux density) are $40 \mathrm{mT}$ for the population and $200 \mathrm{mT}$ for employees [2], whereas the Earth's magnetic field ranges from 30 to $60 \mu \mathrm{T}$, depending on the Earth's position. Concerning time-variant fields, the exposure is limited to EMFs [3,4]. Regarding multiple frequency sinusoidal exposure, the ICNIRP [4] states that all contributions should be considered cumulative so that the following global limit can be met:

$$
\sum_{j=1 \mathrm{~Hz}}^{10 \mathrm{MHz}} \frac{B_{j}}{B_{\text {limit }, j}} \leq 1
$$

where $B_{j}$ is the field magnitude at each given frequency and $B_{\text {limit }, j}$ is the reference level corresponding to that frequency. The expression for the magnetic field $H$ is analogous. IEEE C95.6 [8] is a standard defining the exposure level to protect humans against adverse effects from exposure to electric and magnetic fields at frequencies from 0 to $3 \mathrm{kHz}$. Because none of the above reviews concluded that any hazard from long-term exposure has been confirmed, the standard IEEE C95.6 [8] does not propose limits on exposures necessary to protect against adverse short-term effects.

The ICNIRP issued a new recommendation for the area up to $1 \mathrm{~Hz}$ (also called static EMG fields) as a peak-to-peak limit in 2014 [5]. The shift occurred in the views on the rate of magnetic induction change defined by the parameter $d B / d t$.

If the MF exceeds a threshold by approximately $2 \mathrm{~T}$, the field may be strong enough to cause dizziness and other sensory sensations such as a metallic taste in the mouth, according to the manual $[5,10]$. Oravec [11] considers these effects of MFs to be safe, but they may negatively affect one's ability to work. At present, the ICNIRP considers MFs with a value of $8 \mathrm{~T}$ to be the threshold for limiting peripheral nervous system activity [12]. The threshold of $8 \mathrm{~T}$ provided by the ICNIRP for limiting the peripheral nervous system holds only at frequencies below $1 \mathrm{~Hz}$. A separate group consists of chemical changes in human metabolism resulting from the influence of MFs [11]. The changes are not considered significant if the density of the magnetic flux is less than $7 \mathrm{~T}$ [13]. This fact is supported by MRI devices [14].

For the purpose of measuring the limit values for the $d B / d t$ change, the reference levels at a frequency of $1 \mathrm{~Hz}$ recommended today are

$$
\frac{d B_{0}}{d t}=2 \pi f \sqrt{2} B_{R M S},\left[\mathrm{~T} \cdot \mathrm{s}^{-1}\right]
$$

To calculate the magnetic induction over time, the parameter of the root mean square $B_{R M S}$ is recommended:

$$
B_{R M S}=\sqrt{\frac{1}{t_{2}-t_{1}}} \int_{t_{1}}^{t_{2}}[B(t)]^{2} d t,[T]
$$

Current knowledge suggests the importance of dealing with sources with frequencies up to $3 \mathrm{kHz}$, which are in the three frequency ranges according to the ICNIRP [5], namely 1-8 Hz, 8-25 Hz, and 25-3000 Hz. Frequencies of 0-1 Hz form a separate group considered static from a frequency point of view.

The SBM 2008 [9] standard (amendment 2015) classifies a source into four categories: up to $20 \mathrm{nT}, 20-100 \mathrm{nT}, 100-500 \mathrm{nT}$, and above $500 \mathrm{nT}$. In comparison with the ICNIRP [5], it also contains a recommendation for time-based exposure to MFs and gives preconditions for dosimetric measurements. A separate group consists of epidemiological studies where the MF limit is recommended to be $500 \mathrm{nT}$ [15].

The influence of MFs on humans is influenced by several factors, such as the distance from the source of the MF, objects standing between the source of radiation and the person, and the output (directional characteristic) of the source. In technical practice, $50-$ or $60-\mathrm{Hz}$ MF devices are most frequently used. Only some devices and procedures use sources with 
frequencies below $50 \mathrm{~Hz}$. There are also processes [16,17] which use frequencies lower than $50 \mathrm{~Hz}$ (e.g., demagnetization, welding and special drives). These sources have been given minimum attention. The issue of the impact of MFs on technical equipment is addressed in the field of compatibility $[13,18]$. The second area is the impact of MFs on humans. This issue is treated within work safety, working environment, and work hygiene [11,19].

The MF measurements performed near the EV charging stands detected, at a distance of $10 \mathrm{~cm}$ from the stand, values of $B_{R M S}<50 \mu \mathrm{T}$ at currents up to $200 \mathrm{~A}$ [20]. Some of the measurements indicated that the limit values for MFs in the vicinity of up to $10 \mathrm{~cm}$ from the cover of the stand were exceeded [21].

The asymmetric effect of the interaction between the source and the biological material can be observed even at small values of the MF in animals and humans. The difference in approach between the SBM and the ICNIRP indicates a discrepancy in this issue. Electro mobility raises further questions in this area.

\section{The Situation in Slovakia}

EU Directive 2013/35/EU [6] was reflected in Slovakia in Act No. 355/2007, Coll. [22] on the protection, promotion, and development of public health. The limit values for MFs are given in Slovak Republic Regulation No. 344/2020 [23] (Table 1), which are based on the requirements of the EU Directive 2013/35/EU [6], IEEE C95.6 [8], and ICNIRP standards $[4,5]$.

Table 1. Magnetic induction values $B$ from $1 \mathrm{~Hz}$ to $10 \mathrm{MHz}$ (Slovak Republic) [23].

\begin{tabular}{cccc}
\hline Frequency Band & $\begin{array}{c}\boldsymbol{B}_{a, \text { lower }}[\boldsymbol{\mu T} \text { (Effective } \\
\text { Values) Citizen }\end{array}$ & $\begin{array}{c}\boldsymbol{B}_{a, \text { higher }}[\boldsymbol{\mu T} \text { (Effective } \\
\text { Values) Staff }\end{array}$ & $\begin{array}{c}\boldsymbol{B}[\boldsymbol{\mu} \text { T] for the MF Exposure } \\
\text { of Limbs (Effective Values) }\end{array}$ \\
\hline $1 \mathrm{~Hz} \leq \mathrm{f}<8 \mathrm{~Hz}$ & 0.05 & 0.05 & 0.04 \\
$8 \mathrm{~Hz} \leq \mathrm{f}<25 \mathrm{~Hz}$ & 0.1 & 0.1 & 0.06 \\
$25 \mathrm{~Hz} \leq \mathrm{f}<300 \mathrm{~Hz}$ & 0.21 & 0.16 & 0.08 \\
$30 \mathrm{~Hz} \leq \mathrm{f}<3 \mathrm{kHz}$ & 0.24 & 0.27 & 0.09 \\
$3 \mathrm{kHz} \leq \mathrm{f} \leq 10 \mathrm{MHz}$ & 0.17 & 0.19 & 0.06 \\
\hline
\end{tabular}

The MF exposure evaluation of the population is carried out by assessment, measurement, or calculation [24]. The values obtained are compared with the so-called action values [24], which must not be exceeded in places citizens can access. The experimental procedure was assigned by Bulletin of the Ministry of Health of the Slovak Republic No. 36/2019 [25], which applies to measuring systems and systems for processing measured data with a frequency range from $100 \mathrm{kHz}$ to $6 \mathrm{GHz}$, which can be extended up to $300 \mathrm{GHz}$ if required, according to the Bulletin of the Ministry of the Health of Slovak Republic No. 36/2019 [25], and it is necessary to follow the given methodological instructions OOFŽP-7674/2010 [24]. Measurements below $100 \mathrm{KHz}$ are not regulated by national regulations.

Regulation 344/2020 Coll. [23] (Table 1) does not have a definition of exposure time. The term "short-term exposure" in 344/2020 Coll. [23] is not sufficient to define the amount of MF energy received over time by an object which has been exposed to a magnetic field. Especially with pulsed MF shocks (dynamic radiation change), this problem is apparent. This also implies the incorrect name "exposure action value". The value for this variable is $B$, which is a designation for magnetic flux density and not for doses (Table 1$)$. The term exposure is generally bound to a time frame [11]. Failure to consider the vector substance of MFs, similar to the ICNIRP standards [3-5], leads to ambiguity in the measurement and in the interpretation of the measured values. Depending on the method of measurement and the position of the measuring equipment relative to the source, components $B_{x}, B_{y}$, and $B_{z}$ in the $\mathrm{x}, \mathrm{y}$, and $\mathrm{z}$ directions can be measured from a rectangular orthogonal system, and the resulting magnetic induction vector is

$$
\vec{B}=\vec{B}_{x}+\vec{B}_{y}+\vec{B}_{z},[\mathrm{~T}]
$$


The size of the resulting magnetic induction vector $B_{\text {total }}$ is

$$
B_{\text {total }}=\sqrt{B_{x}^{2}+B_{y}^{2}+B_{z}^{2}},[\mathrm{~T}]
$$

The $B_{R M S}$ value is a scalar value. Measurements of the limit values made according to the ICNIRP standards [4,5] were performed for stable sources in Slovakia [26,27]. This is questionable in the case of EV charging. An EV is a mobile device with a built-in converter. In the case of an EV charging stand, these standards can have limited use, taking into account the vector nature of MFs.

The development of electro mobility and charging stations is not sufficiently covered normatively. The ICNIRP limit values as well as the norms in the Slovak Republic are for stable sources. An electric car cannot be considered a stable source.

\section{Materials and Methods}

\subsection{Experimental Method and Experimental Equipment}

Each object with an electric charge has its local MF characterizing its status and operation. The MF of the object is formed by the movement of machine elements (e.g., moving, rotating machine elements in the MF of the Earth), which modulate the local MF of the source. The second source of local MF production is the flow of current through electrical devices (e.g., winding of transformers and converters). Equipment for measuring the induced local MF through an electric device was carried out by Oravec et al. as utility model UV8860 [28] and as utility model UV 50084-2019 [29]. Quantification of the MF parameters of the object is possible within the time and frequency range. A discrete fast Fourier transform (DFT) can help analyze the frequency area in detail. Many measurements were made $[17,27]$, mainly in the area of non-contact measurements, confirming the suitability of the method and the VEMA-041 magnetometer. The VEMA-041 is a purpose-built measuring device designed for the measurement of MFs [30-32] for the needs of military aviation. Compared with industrial measuring devices such as those from NARDA [26], the VEMA-041 is more accurate. The frequency range of the VEMA-041 is $0-250 \mathrm{~Hz}$, and the magnetic induction density range is from $2 \times 10^{-9} \mathrm{~T}$ to $2 \times 10^{-5} \mathrm{~T}$ with a sensitivity of $1.7 \mathrm{nT}$. The same fluxgate principle proved useful in attitude determination of the satellites skCUBE [13,30,33,34] and GRBAlpha in 2021 [35] in Earth's MF.

\subsection{Measurement and Evaluation of Experimental Data}

The evaluation (both in real time and for post-processing) utilized OtVema (opensource) software. This software enables processing of data collected by a magnetometer. The software's primary functions are the visualization of processed data for the user and data recording in accordance with a selected time schedule. Files of magnetometer data are processed and displayed in an oscilloscopic mode on the screen. Figure 1 shows the entire measurement chain used for the measurement $[29,36]$.

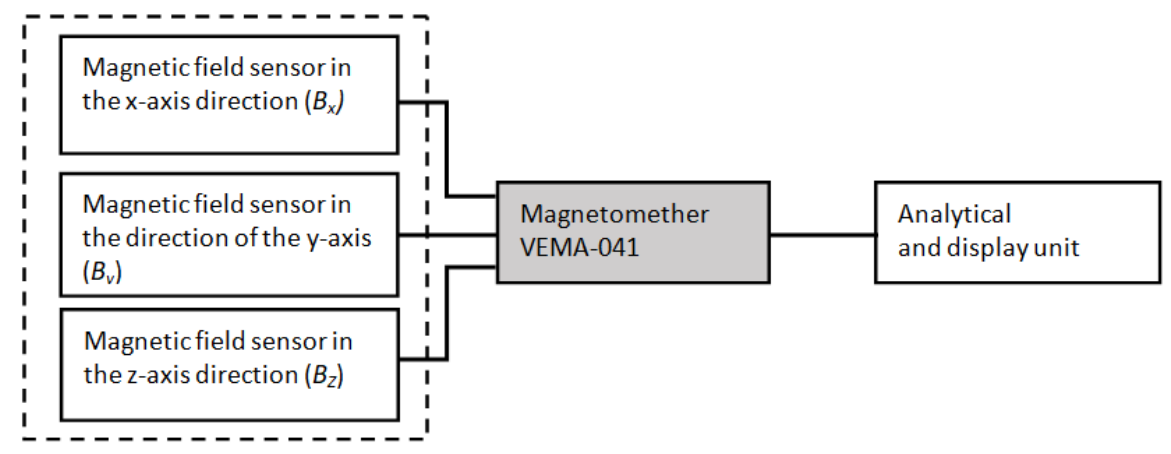

Figure 1. Measurement chain and sensor on basic of fluxgate principle. 
For the post-processing options in the QtVema environment for MF analysis and $d B / d t$ changes, we selected a display of the frequency spectra, which is a display of the position of the resulting point of the MF parameter of the rotating vector. The rotating vector of the MF has already been presented in the past [37] but was not used in direct experiments. The reason for this was the difficulty of data processing and understanding the local gradient (acyclic) of the MF around the device. The QtVema environment has the tools to accomplish this, and evaluation can be performed online (QtiPlot 0.8.5 in OS GNU/Linux distribution UBUNTU 6.06). The sensitivity of the VEMA-04 magnetometers was $1.7 \mathrm{nT} / \mathrm{LSB}$ (least significant bit). Full-scale non-linearity was below $0.5 \%$ in the measurement range of $\pm 60 \mu \mathrm{m}$. The channels were sampled simultaneously at a rate of 1000 samples per second. The noise spectral densities of the used magnetometers were identified experimentally with long-term measurements and also with the method presented in [33], which were

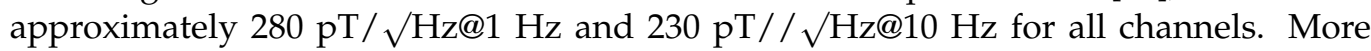
information is in $[33,34]$, and the error rate of the VEMA-041 measuring device is listed in [38].

\subsection{The Course of the Experiment}

The MF represented by parameter $B$ near the EV charging stand is dependent on the current and charging power. The charging power is a function of the current and the operating voltage.

The charging of the EV was analyzed using two charging stands. In the first case, it was charged up to $6.6 \mathrm{~kW}$. In the second case, it was charged via the fast charger, with a charging power of $43 \mathrm{~kW}$. The analysis was carried out along the entire energy flow chain. The energy flow chain was formed by a transformer, underground cables, and a charging stand. The analysis included an EV charging assessment with a built-in AC/DC converter inside the EV. EV samples of the same make in the first and second generation were used for the measurement. Transformers up to $250 \mathrm{~kW}(22 \mathrm{~kW} / 400 \mathrm{~V})$ were used. The cables leading up to the stand passed through the ground or the building itself, depending on the location. The experiments were carried out during EV charging. The measurement was carried out at a distance of $0.3 \mathrm{~m}$ from the floor stand, at a height of $0.40 \mathrm{~m}$, and on the $\mathrm{AC} / \mathrm{DC}$ EV converter in the EV engine compartment, (Figure 2) as well as in the driver's footwell and the driver's seat area (under the seat).

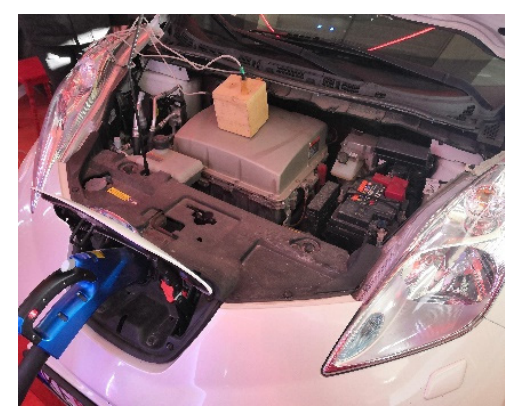

(a)

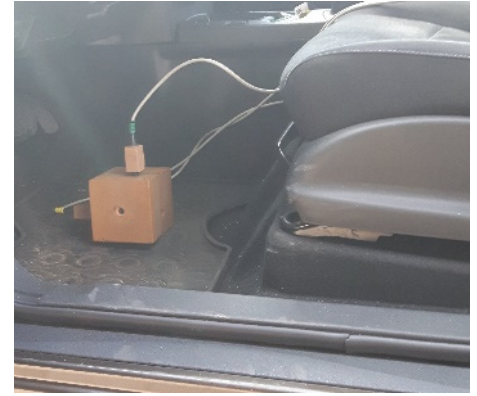

(b)

Figure 2. Location of the measuring prism during MF measuring. (a) in EV's motor; (b) in in the footwell in EV.

\section{Results}

\subsection{Electricity Transmission and Its Transformation}

The MF measurement was made on a three-phase insulated cable leading to the transformer with a current of $600 \mathrm{~A}$ at a distance of $1 \mathrm{~m}$. The measuring prism was positioned such that the direction of the " $x$ " axis was in the direction of the imaginary flow of electrical energy. The " $y$ " and " $z$ " axes formed a rectangular orthogonal system with the " $\mathrm{x}$ " axis. Figure 3 shows the time courses of $B_{x}, B_{y}$, and $B_{z}$ in the $\mathrm{x}, \mathrm{y}$, and $\mathrm{z}$ directions without a one-way component (filtered static component MF). 


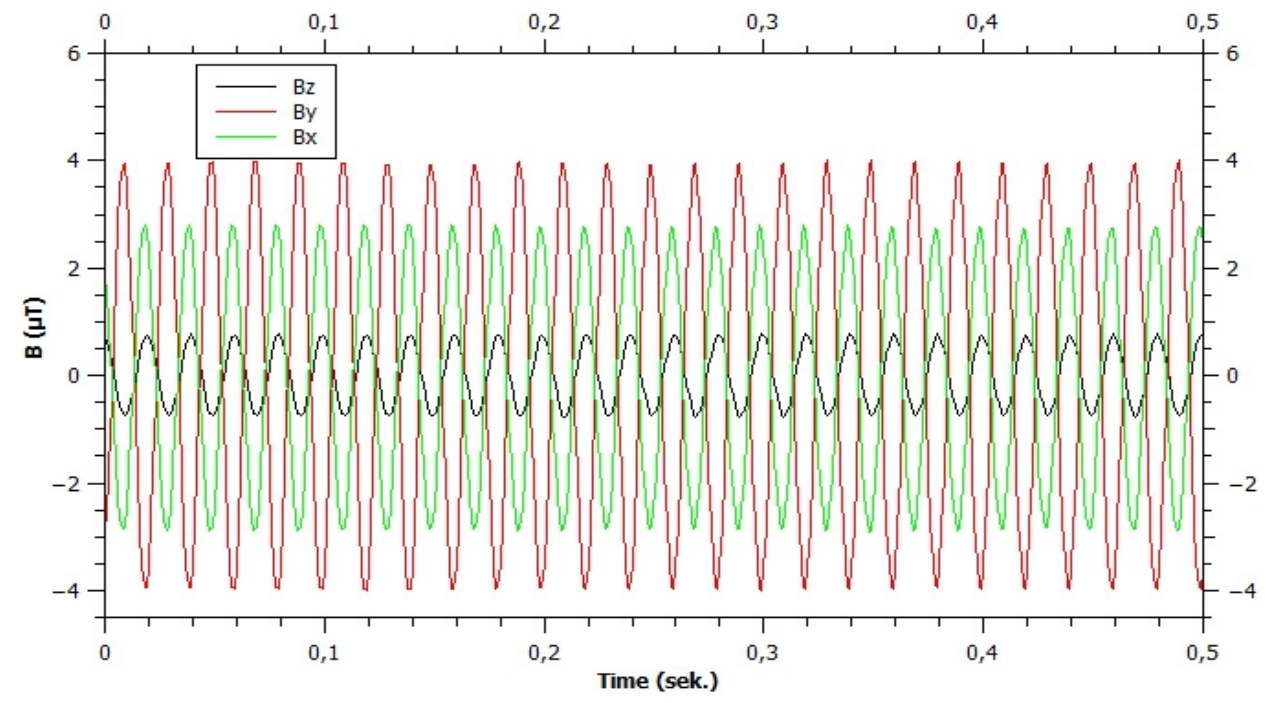

Figure 3. Time course of $B_{x}, B_{y}$, and $B_{z}$ without the one-way component.

The time recording of the MF measurement in the footwell was analyzed by the DFT method during the post-processing process. Figure 4 shows the $B_{x}, B_{y}$, and $B_{z}$ spectra from the time course in Figure 3.

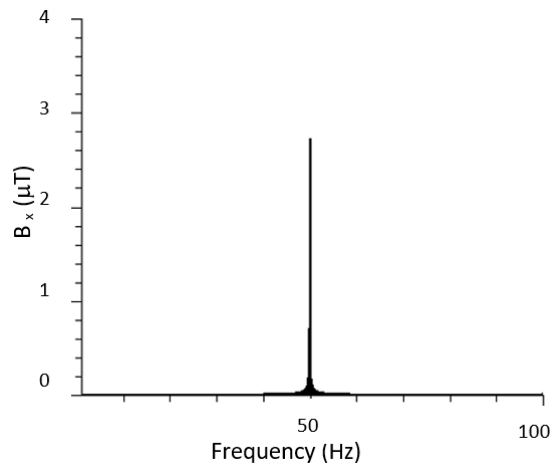

(a)

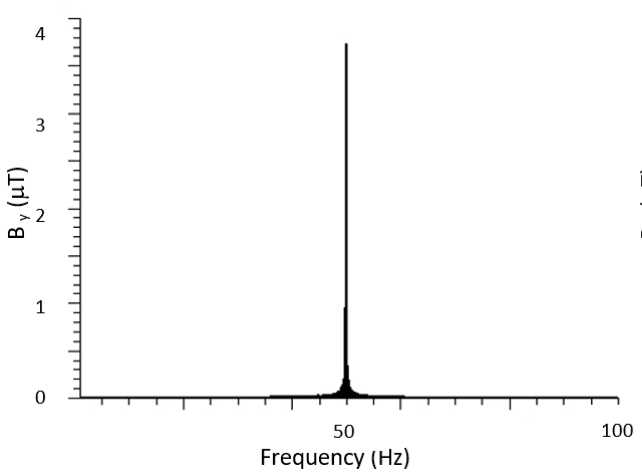

(b)

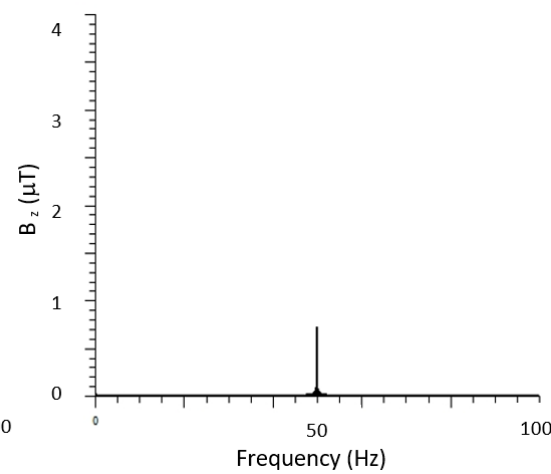

(c)

Figure 4. Graphs showing the $B_{x}, B_{y}$, and $B_{z}$ spectra for the three-phase power insulated cable $(600 \mathrm{~A})$ at a distance of $1 \mathrm{~m}$. (a) in the " $x$ " axis direction; (b) in the " $y$ " axis direction; (c) in the " $z$ " axis direction.

Figure 4 displays values of $B_{x}=2.71 \mu \mathrm{T}, B_{y}=3.7 \mu \mathrm{T}$, and $B_{z}=0.7 \mu \mathrm{T}$ at $50 \mathrm{~Hz}$. In terms of Equations (3) and (5), a value of $B_{R M S}=3.25 \mu \mathrm{T}$ was calculated. This value was lower than the limit value stated in Table 1 for a frequency of $50 \mathrm{~Hz}$ for all three action levels.

The measured MF values correlated with the values published from 1998-2021 [39-41]. For $400-\mathrm{kV}$ cables in the ground, the $0.05-\mu \mathrm{T}$ values were measured on the surface of the ground [42]. For cables in houses and office buildings with a current up to $30 \mathrm{~A}$, values up to $1 \mu \mathrm{T}$ were measured for older cables up to a distance of $0.3 \mathrm{~m}$. For three-phase power cables up to $600 \mathrm{~A}$, values of $5 \mu \mathrm{T}$ were measured up to a distance of $2 \mathrm{~m} \mathrm{[43].} \mathrm{The} \mathrm{texts} \mathrm{of}$ published contributions are not clear about whether these are effective or absolute values, and they are, therefore, only indicative. This fact can be seen in several epidemiological studies [44-47] without defining the parameters of the MF source and the distance from the source.

The charging stands are powered by transformers. The measurements were made on two transformers with different power values and one distribution box. The first measurement was carried out on a $250-\mathrm{kVA}$ transformer located in a brick building. The measuring prism was located $1 \mathrm{~m}$ from the perimeter wall of the transformer. The " $\mathrm{x}$ " axis 
was perpendicular to the perimeter wall, and the " $y$ " and " $z$ " axes formed a rectangular orthogonal system with the " $x$ " axis. The second transformer, with $100 \mathrm{kVA}$ of power, was placed on the ground. The measuring prism was placed $1 \mathrm{~m}$ from or at the edge of the object. The detected frequencies from the frequency analysis of the transformers and the distribution box serving as the power supply of the EV charging stands are stated in Table 2.

Table 2. Detected amplitudes $B$ at a frequency of $50 \mathrm{~Hz}$ for selected transformers.

\begin{tabular}{|c|c|c|c|c|}
\hline $\begin{array}{l}\text { Magnetic } \\
\text { Induction }\end{array}$ & $\begin{array}{l}\text { Frequency } \\
\quad(\mathrm{Hz})\end{array}$ & $\begin{array}{c}\text { Transformer * } \\
250 \mathrm{kVA} \\
(22 \mathrm{kV} / 400 \mathrm{~V})\end{array}$ & $\begin{array}{c}\text { Distribution } \\
\text { Box near the } \\
\text { Transformer ** } \\
250 \mathrm{kVA} \\
(22 \mathrm{kV} / 400 \mathrm{~V})\end{array}$ & $\begin{array}{c}\text { Transformer } \\
100 * * \\
(22 \mathrm{kV} / 400 \mathrm{~V})\end{array}$ \\
\hline$B_{x}(\mu \mathrm{T})$ & & 1.27 & 3 & 0.82 \\
\hline$B_{y}(\mu \mathrm{T})$ & & 0.97 & 0.7 & 0.3 \\
\hline$B_{z}(\mu \mathrm{T})$ & 50 & 0.37 & 0.7 & 0.35 \\
\hline$B_{R M S}(\mu \mathrm{T})$ & & 1.15 & 2.21 & 0.66 \\
\hline$B_{a, \text { lower }}(\mu \mathrm{T})$ & & \multicolumn{3}{|c|}{$1000 \mu \mathrm{T}$ (limit according to Table 1 ) } \\
\hline
\end{tabular}

In the case of a transformer with a power of $100 \mathrm{kVA}$, the third and fifth harmonics in the direction of the $\mathrm{z}$ axis were also identified; however, they were negligible compared with the first harmonic. The measurement of components $B_{x}, B_{y}$, and $B_{z}$ enabled the identification of the direction in which the maximum magnetic field value was applied. The resulting rotating vector MF [38] provided information not only about the position and pulse of the MF but also the errors [48]. At the same time, it is possible to point out the possibilities of interpretation of measured MP values. The vector position MP enables statistical evaluation, detection of machine failures, and knowledge of the causality of an event. These methods of evaluation can be used in technical diagnostics as well as measurements focused on the interaction of the "source of MP-man (operator)". Figure 5a shows the end of the rotating vector $B_{\text {total }}$ for a field of a cable with a current of $600 \mathrm{~A}$ at a distance of $1 \mathrm{~m}$. The rotating vector MP in Figure $5 \mathrm{a}$ is a closed ellipse, which determines a cyclic phenomenon at one frequency. Said frequency is shown in Figure $4(50 \mathrm{~Hz})$. Figure $5 \mathrm{~b}$ shows the end of a rotating vector $B_{\text {total }}$ of a transformer with a power of $250 \mathrm{kVA}$ at a distance of $1 \mathrm{~m}$ from the wall of the object. Blue represents the minimums, and red represents the peaks. The position and size of this vector determine spots with increased MF pulse values. Indirectly, the amplitude spectra (Figure 4) indicate the end point of the $M F$ vector. QtVema works in a coordinate system of $A, B$, and $C$, corresponding to $A=x$, $\mathrm{B}=\mathrm{y}$, and $\mathrm{C}=\mathrm{z}$.

The transformer, compared with the cable, is a more complex device, and manufacturing inaccuracies and the operating load can also cause odd harmonics that change the image of the rotating $B_{\text {total }}$ (Figure $5 \mathrm{~b}$ ). The transformer measurements also determined odd harmonics (third and fifth), and the MP image was no longer an ellipse. The rotating vector MP was closed, as it was a cyclically repeating phenomenon. Similarly, sources in the electrical network can generate multiples of $50 \mathrm{~Hz}$ [18]. The width of the pattern trace indicated the presence of higher harmonics in the transformer. The location of the end of the rotating vector was displayed online in the QtVema environment. 


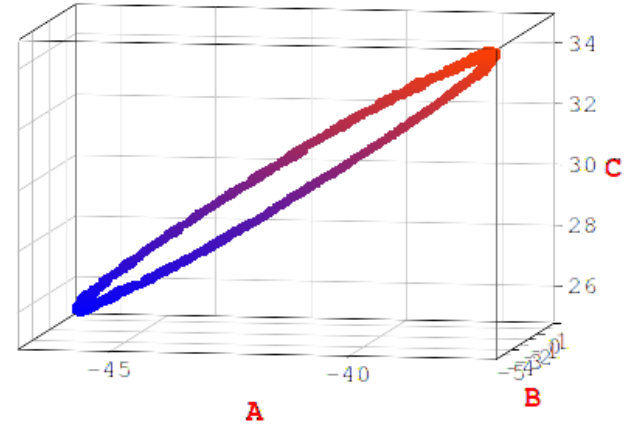

(a)

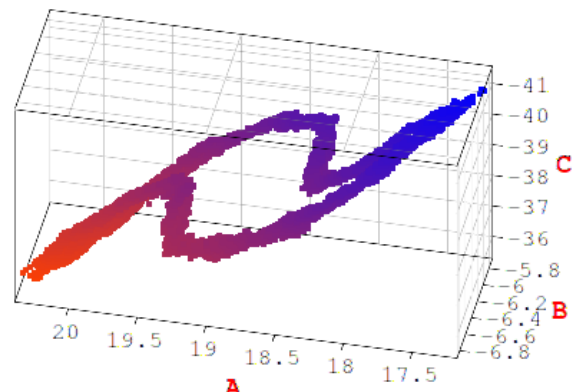

(b)

Figure 5. The end position of the rotating vector $B_{\text {total }}$ of magnetic induction of the cable (a) and transformer (b).

The $B_{R M S}$ value for the $250 \mathrm{kVA}$ and $100 \mathrm{kVA}$ transformers and the distribution box complied with the limit values (Table 2) for the frequency of $50 \mathrm{~Hz}$ for all three levels.

Many epidemiological studies [49-55] assess the effects on health in the vicinity of transformers in residential houses. The measured values of MF did not exceed $5 \mu \mathrm{T}$ at $50 \mathrm{~Hz}$. The repeatability of these trials is questionable, however, as the distances from the source and the output of the source were not clearly defined. Wide frequency range equipment was used. Only the $B_{R M S}$ value, which was a scalar, was measured. The results can be used for the indicative determination of the interval of $B$ values in the vicinity of transformers. Measurements on the transformers were made at $50 \mathrm{~Hz}(60 \mathrm{~Hz})$.

\subsection{AC/DC Converter}

\subsubsection{Charging with an Inverter Built into the EV}

The first measurements were made with the first generation of the Nissan Leaf EV. The charging power was $6.6 \mathrm{~kW}$ at $16 \mathrm{~A}$. The position of the converter in the EV was in the space in front of the driver's seat at the level of the steering wheel in the front hood compartment (Figure 2a). The distance between the converter and the position of the measuring prism was less than $1 \mathrm{~m}$. Similarly, as in the case of the cable and transformer, frequency domain analysis was performed (Figure 6).

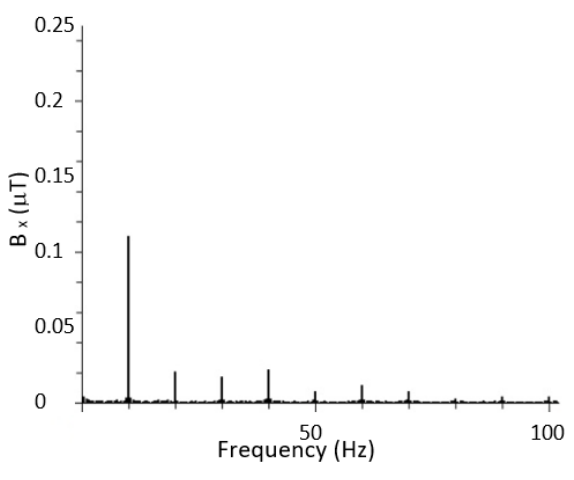

(a)

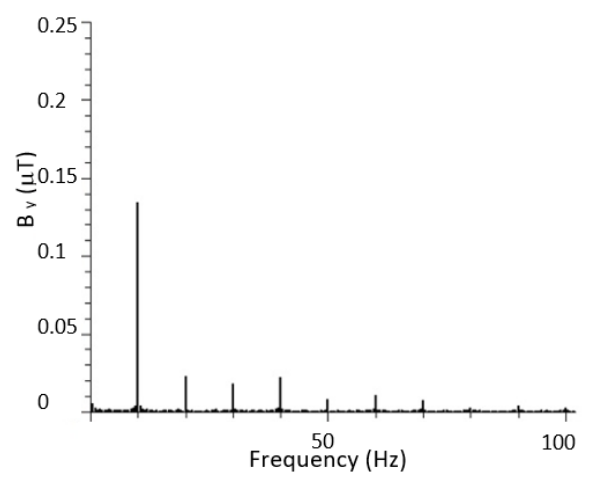

(b)

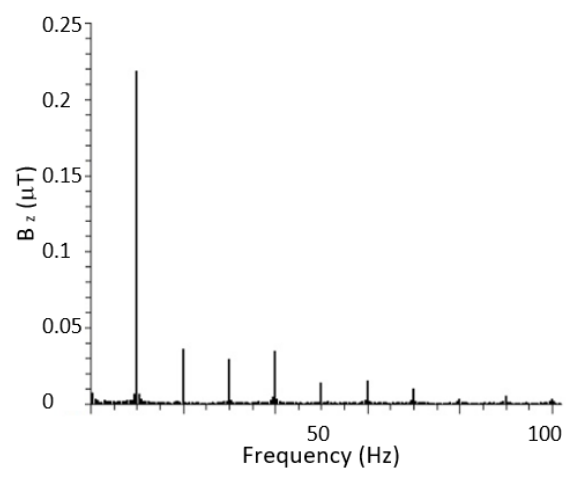

(c)

Figure 6. Magnetic induction values $B_{x}, B_{y}$, and $B_{z}$ in the $x, y$, and $z$ directions in the footwell of the EV driver. (a) in the " $x$ " axis direction; $(\mathbf{b})$ in the " $y$ " axis direction; $(\mathbf{c})$ in the " $z$ " axis direction.

Several frequencies can be observed compared with the cable and transformer. These frequencies were caused by the design of the AC/DC converter in the EV. The basic frequency was $10 \mathrm{~Hz}$, and the harmonic multiples were derived from it. The values of the $B_{x}, B_{y}$, and $B_{z}$ amplitudes correspond to the current during charging. The image created by rotating the end point of the $B_{\text {total }}$ vector was closed and cyclic. Table 3 shows the magnetic induction values of $B$ for the individual frequencies shown in Figure 6. The ratio 
of the measured value to the limit value B according to Equation (1) was less than one. In the case of the transformer, it can be claimed that in terms of the Slovak legislation, this condition would be satisfactory if this were a stable source for all the action levels. Similarly, the magnetic induction values were measured in the space of the driver seat (Figure 3). A similar finding would be made with regard to the ratio of the action level limit value to the measured values of the MF. The fact is that an EV is a mobile device.

Table 3. The amplitude(s) determined for the respective frequencies. Measurement: footwell of the driver (6.6 kW).

\begin{tabular}{lccccccc}
\hline \multirow{2}{*}{$\begin{array}{c}\text { Magnetic } \\
\text { Induction }\end{array}$} & \multicolumn{7}{c}{ Frequency (Hz) } \\
\cline { 2 - 8 } & $\mathbf{1 0}$ & $\mathbf{2 0}$ & $\mathbf{3 0}$ & $\mathbf{4 0}$ & $\mathbf{5 0}$ & $\mathbf{6 0}$ & $\mathbf{7 0}$ \\
\hline$B_{x}(\mu \mathrm{T})$ & 0.11 & 0.020 & 0.017 & 0.022 & 0.001 & 0.0012 & 0.007 \\
$B_{y}(\mu \mathrm{T})$ & 0.134 & 0.022 & 0.017 & 0.22 & 0.01 & 0.011 & 0.008 \\
$B_{z}(\mu \mathrm{T})$ & 0.217 & 0.036 & 0.029 & 0.034 & 0.014 & 0.016 & 0.010 \\
$B_{\text {lower }}(\mu \mathrm{T})$ & 0.28 & 0.05 & 0.04 & 0.22 & 0.02 & 0.02 & 0.01 \\
$B_{R M S}(\mu \mathrm{T})$ & 0.19 & 0.03 & 0.03 & 0.16 & 0.01 & 0.01 & 0.01 \\
$B_{a, \text { lower }}(\mu \mathrm{T})$ & $2.5 \times 10^{3}$ & $2.5 \times 10^{3}$ & $1 \times 10^{3}$ & $1 \times 10^{3}$ & $1 \times 10^{3}$ & $1 \times 10^{3}$ & $1 \times 10^{3}$ \\
$B_{R M S, j} / B_{\text {limit, } j}$ & $7.77 \times 10^{-5}$ & $1.31 \times 10^{-5}$ & $2.64 \times 10^{-5}$ & $1.57 \times 10^{-4}$ & $1.21 \times 10^{-5}$ & $1.36 \times 10^{-5}$ & $1.02 \times 10^{-5}$ \\
\hline
\end{tabular}

Table 3 clearly shows the substantial representation of the emitted energy of the MF at the frequencies $10 \mathrm{~Hz}$ and $40 \mathrm{~Hz}$. The maximum value of the emitted magnetic induction was in the " $z$ " direction. At a frequency of $10 \mathrm{~Hz}$, in the " $x$ " axis direction, it was $24 \%$; in the " $y$ " axis direction, it was $29 \%$; and in the " $z$ " axis direction, it was $47 \%$. The design and location of the changer were decisive for these values.

\subsubsection{Charging with Charging Stand at $43 \mathrm{~kW}$ Charging Power}

The second measurement was made when charging from the $175-\mathrm{kW}$ fast charging stand. The power to be transmitted was $43 \mathrm{~kW}$. The MF occurring in the stand in front of the charging stand at a distance of $0.5 \mathrm{~m}$ and at a height of $0.4 \mathrm{~m}$ from the ground is displayed in (Figure 7). The " $x$ " axis direction was oriented toward the stand, whereas " $y$ " was positioned horizontally, and " $z$ " was positioned vertically. The axes formed a rectangular orthogonal system.

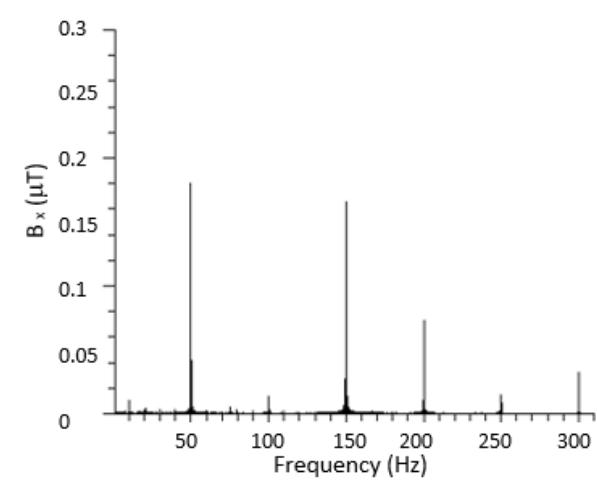

(a)

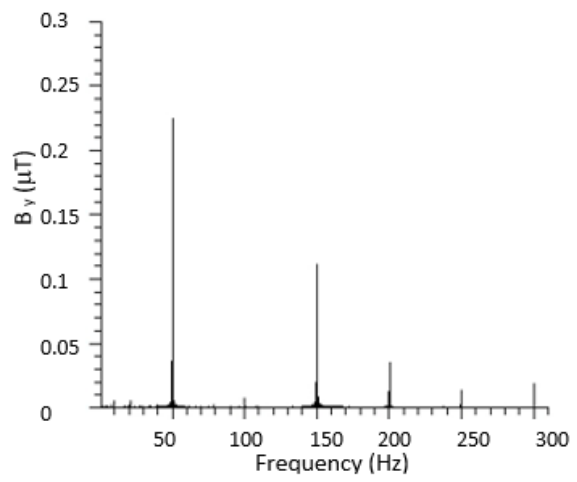

(b)

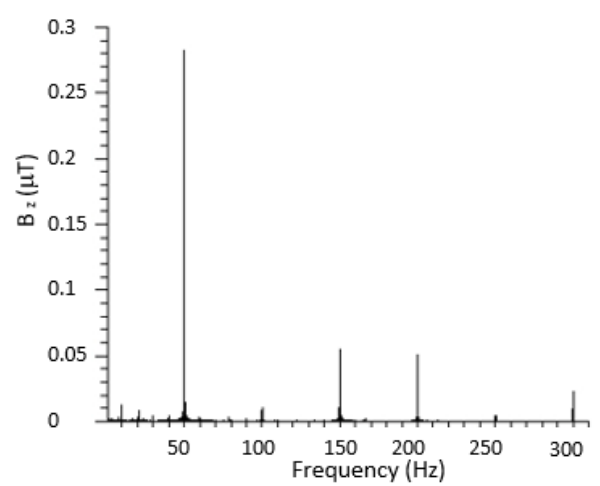

(c)

Figure 7. Magnetic induction values $B_{x}, B_{y}$, and $B_{z}$ in in the $x, y$, and $z$ directions in front of the charging stand. (a) in the " $x$ " axis direction; $(\mathbf{b})$ in the " $y$ " axis direction; $(\mathbf{c})$ in the " $z$ " axis direction.

In order to identify the MF in the EV compartment, a measuring prism was placed on the AC/DC converter in the engine compartment (Figure 2a). Figure 8 shows the amplitude spectra measured at the AC/DC converter. 


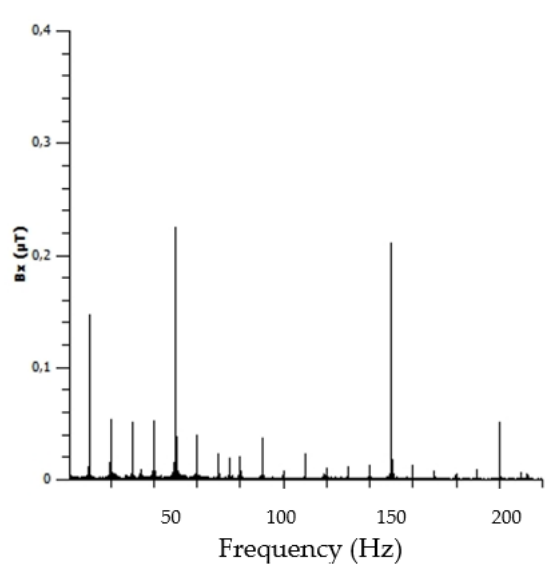

(a)

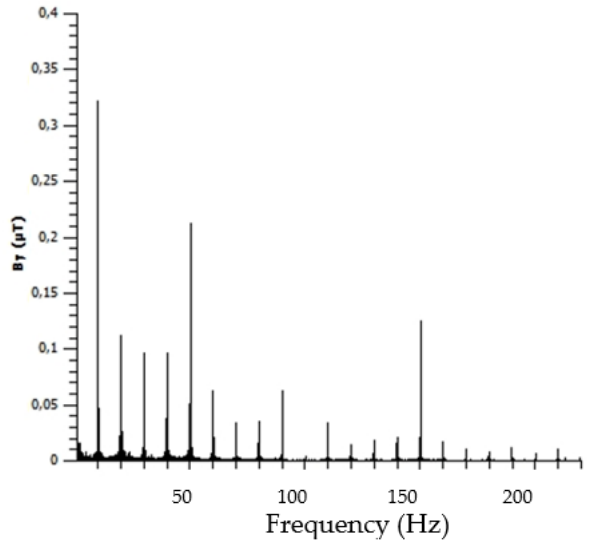

(b)

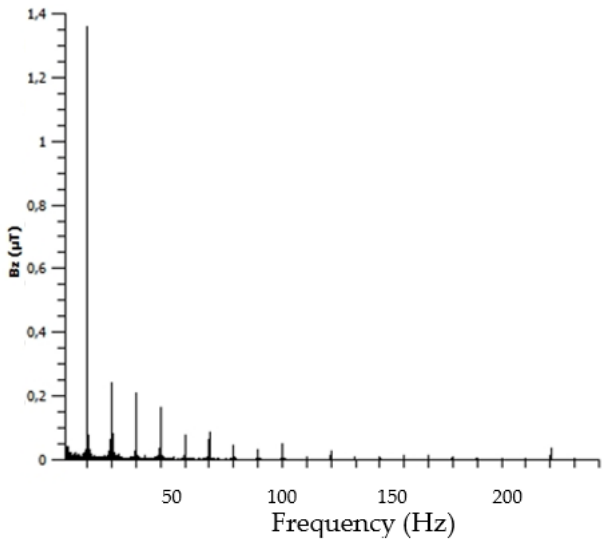

(c)

Figure 8. Magnetic induction values $B_{x}, B_{y}$, and $B_{z}$ for the AC/DC converter in the engine compartment of the EV. (a) in the " $x$ " axis direction; (b) in the " $y$ " axis direction; $(\mathbf{c})$ in the " $z$ " axis direction.

By comparing Figures 7 and 8, it is clear that the $50-\mathrm{Hz}$ frequency and its multiples were from the charging stand. The built-in AC/DC converter in the EV worked with a basic frequency of $10 \mathrm{~Hz}$ and its multiples.

By comparing the amplitude spectra for the cable (Figure 4), transformer (Figure 8), and spectra in Figure 9, it was obvious that the trajectory pattern of the resulting MF $B_{\text {total }}$ vector at the $\mathrm{AC} / \mathrm{DC}$ converter station would be different (Figure 9). Blue shows the minima, and red shows the peaks $B_{\text {total }}$. QtVema works with the coordinate system A, B, and $C$, in which $A=x, B=y$, and $C=z$.

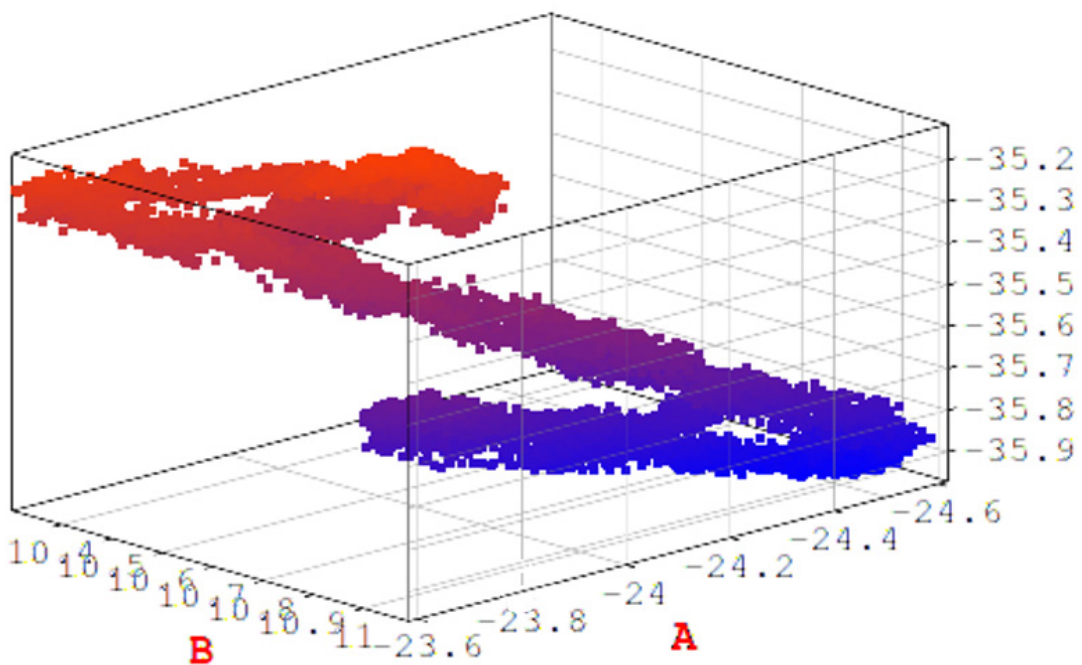

Figure 9. The end position of the rotating vector $B_{\text {total }}$ of the magnetic induction of the AC/DC converter in the EV for the spectra in Figure 6.

The change in polarity of $B_{\text {total }}$ is shown in blue and red (Figure 9). The track width indicates the presence of multiple frequencies oscillating around a fundamental frequency of $10 \mathrm{~Hz}$, which is evident from the spectrum analysis of Figure 6. The Z-shaped MP shape (top view) revealed the change. The rotating vector MP was closed, which indicates the cyclicality of the process.

The minimum and maximum values of $B x, B y$, and $B z$ can be subtracted from the MP shape as illustrated in Table 4 . The mean value of the MP (static component) was in the center of the MP pattern around which the rotating MP vector oscillated. 
Table 4. The amplitude(s) detected for the corresponding frequencies in the footwell of the driver (43 kW).

\begin{tabular}{lccccccc}
\hline \multirow{2}{*}{$\begin{array}{c}\text { Magnetic } \\
\text { Induction }\end{array}$} & \multicolumn{7}{c}{ Frequency (Hz) } \\
\cline { 2 - 8 } & $\mathbf{1 0}$ & $\mathbf{2 0}$ & $\mathbf{3 0}$ & $\mathbf{4 0}$ & $\mathbf{5 0}$ & $\mathbf{6 0}$ & $\mathbf{7 0}$ \\
\hline$B_{x}(\mu \mathrm{T})$ & 0.15 & 0.06 & 0.05 & 0.05 & 0.22 & 0.04 & 0.03 \\
$B_{y}(\mu \mathrm{T})$ & 0.32 & 0.11 & 0.1 & 0.1 & 0.21 & 0.06 & 0.02 \\
$B_{z}(\mu \mathrm{T})$ & 1.35 & 0.24 & 0.21 & 0.16 & 0.08 & 0.08 & 0.09 \\
$B_{\text {lower }}(\mu \mathrm{T})$ & 1.36 & 0.27 & 0.24 & 0.27 & 0.24 & 0.06 \\
$B_{R M S}(\mu \mathrm{T})$ & 0.95 & 0.19 & 0.17 & 0.19 & 0.17 & 0.04 \\
$B_{a, \text { lower }}(\mu \mathrm{T})$ & $2.5 \times 10^{3}$ & $2.5 \times 10^{3}$ & $1 \times 10^{3}$ & $1 \times 10^{3}$ & $1 \times 10^{3}$ & $1 \times 10^{3}$ & $1 \times 10^{3}$ \\
$B_{R M S, j} / B_{\text {limit }, j}$ & $3.81 \times 10^{-4}$ & $7.47 \times 10^{-5}$ & $1.67 \times 10^{-4}$ & $1.88 \times 10^{-4}$ & $1.69 \times 10^{-4}$ & $6.42 \times 10^{-5}$ & $4.08 \times 10^{-5}$ \\
\hline
\end{tabular}

Table 4 also shows, for comparison, specific values in the footwell of the driver. The values are only given up to a frequency of $70 \mathrm{~Hz}$.

The ratio of the measured value to the limit value $B$ according to Equation (1) was less than one for of the footwell of the driver when charging at $43 \mathrm{~kW}$. This result was same as that for $6.6 \mathrm{~kW}$ EV charging. The value of $500 \mathrm{nT}$ was reached in the EV compartment.

A significant proportion of the emitted MP energy could be observed in the " $z$ " axis direction when charging the EV with a power value of $43 \mathrm{~kW}$.

Second-generation Nissan Leaf EVs emit different frequencies. This is clear from the comparison of Tables 4 and 5. Energy was transmitted at a frequency of $10 \mathrm{~Hz}$, which was $55 \%$ of the energy MP, and at a frequency of $40 \mathrm{~Hz}$, it was $11 \%$. The energy transferred at a frequency of $10 \mathrm{~Hz}$ in the " $x$ " axis direction was $8 \%$; in the " $y$ " axis direction, it was $17 \%$; and in the " $\mathrm{z}$ " axis direction, it was 75\% (Figure 8).

Table 5. SBM standard-2015 [9].

\begin{tabular}{lcccc}
\hline & \multicolumn{4}{c}{ Category } \\
\cline { 2 - 5 } & Without & Slight & Significant & Critical \\
\hline $\begin{array}{l}\text { Magnetic } \\
\text { Induction (nT) }\end{array}$ & $<20$ & $20-100$ & $100-500$ & $>500$ \\
\hline
\end{tabular}

\section{Discussion}

The results of the measurements show that EVs are a source of MFs. The ICNIRP manual [5] does not address these conditions, as EVs cannot be considered a stable source when being charged. The opposite is a stable stand or charging station in a building with a transformer and cable. So far, there is no standard for mobile devices. The current locations of charging stands in buildings are, by their nature, closer to the building's hygiene. In the past, unlike with industrial buildings, it was unusual to locate transformers in residential buildings, as is the case in Western Europe. Standards for the hygiene of buildings such as SBM 2015 [9] do not yet have an equivalent in Slovakia [15]. The number of reports at the Slovak Regional Public Health Authority from this area [56] is also indicative of this. MF measurements are performed mainly in industries, where major sources of MFs, electrolysis, induction furnaces, etc. are located.

Fixed charging stations located on the ground in public spaces can be assessed according to the Slovak standards. In this respect, it can be concluded that they are suitable. As shown in Figure 1 and Table 1, the charging stands complied with the $1000-\mu \mathrm{T}$ limit value.

If the charging stand is located on the premises or on the walls of restaurants or residential houses, the purpose must be taken into account, and the standard then needs to be selected accordingly. Recommendation SBM 2015 [9] has stricter limit values (Table 5). In a building with multiple sources of MFs, this problem will become even more noticeable.

The comparison of limit values of magnetic induction in Table 5 and measured values in Tables 2-4 would thus place those sources in the categories of significant to critical accord- 
ing to SBM 2015 [9]. The difference in limit values of more than three orders of magnitude in the field of occupational safety and hygiene in buildings is an existing problem.

The value of $500 \mathrm{nT}$ is also a limit value in several epidemiological studies [54], which have been conducted for different types of residential buildings and sources of MFs. An epidemiological approach does not require precise causality descriptions and use statistical tools. Exposure time in these studies ranged from $24 \mathrm{~h}$ to months.

From the measurement point of view, it was a spot measurement, regardless of the specifications of the source parameters or causality. The above measurements did not consider the vector nature of MFs. The spot measurement of such fields implies having a clearly defined measurement objective and using equivalent procedures. Many epidemiological studies are based on the MF source having an amplitude of $50 \mathrm{~Hz}$ without verification. In fact, the network load and transformer errors cause the presence of the third and fifth harmonic MFs. These facts will cause the shape of the MF pattern to change from an ellipse (Figure $5 a, b$ ).

The rotating vector of an MF at the measuring point (Figures 5 and 9) as well as the spectra in Figures 4 and 6, Figures 7 and 8 point out the need to reconsider the method of measuring MFs. The local MF gradient in space and case where a person is moving may not produce a true image of reality. An MF is of a vector nature. Tools exist to identify MFs, and a dosimetry approach is a possible solution. The magnetic induction parameter, frequency, and time represent the performance of MFs. This MF performance can be quantified [13].

The MF value is not a number but a form of information. Information makes sense if it is known that there is causality, which is a method of change. An MF is a unique source of information about the change in the state of the device, as well as the environment in which a person is located. Today's tools to describe this situation are insufficient. The $B_{R M S}$ value reported in the ICNIRP standards is not sufficient to quantify changes in MFs. There also exists a change in that the one-way component of an MF is not assessed by the ICNIRP standards. The recommendation of change $(0.22 \mathrm{~T} / \mathrm{s})$ for frequencies greater than $1 \mathrm{~Hz}$ is insufficient. The image of an MF also points to other possibilities of evaluating the change in an MF. Changing $d B_{R M S} / d t$ is not enough. There is also a $d B / d t$ change for the unidirectional (static) value of an MF. This is caused by sharp movements of EVs in the Earth's magnetic field, and $d B / d t$ changes make sense when an EV is moving. This problem can be solved by a dosimetric device that will allow for measuring the all-day dose of MF change for the EV crew.

The Slovak Republic does not yet perform dosimetry measurements in the framework of construction procedures, neither for the purpose of fixing the charging stands nor for the purpose of assembling the wall boxes in residential houses. A minimum zone with respect to the surrounding area should be established, defining the possibilities for the locations of stable resources with the potential of low-frequency MFs. The current standards allow charging stations to be placed on one wall, even when there is an office or a living space on the other side of the wall. For sources such as transformers and lines, most of the MF parameters can be determined easily, as they operate at $50 \mathrm{~Hz}$ and its multiples. The opposite is the condition where switch-based (DC/AC) converters are used (photovoltaic systems).

The efficiency of charging stations per unit of power was lower compared with the transformer (Tables 2, 4 and 5). The challenge in constructing charging stands is to use solutions that will emit less MFs into the surrounding areas. This shall also be detected when measuring efficiency with respect to the unit of performance. Compared with the converter used for EV charging, the transformer is more efficient per unit of power than the charging stands (i.e., AC/DC converters). The MF performance parameter is appropriate if the intention is to compare energy losses across different fields that can be analyzed using a DFT. For the built-in inverter in the EV (Figure 2, Tables 3 and 4), the first harmonic multiples in relation to the MF direction were measured at a specific time. On the basis of the above facts, charging of EVs should be carried out with the driver's and passengers' absence, particularly during quick charging. 
Mathematical tools, as well as specific measuring devices, offer options for the application of procedures not only for measuring cyclical courses of MFs but also for pulse spikes [13]. Such phenomena are known from the energetics.

In the area of mobile devices, the component $d B / d t$, due to the change in the direction of movement of the object in the Earth's MF, is also increasing. During rapid braking, EVs can make changes between 5 and $7 \mu \mathrm{T}$ in a quarter of a second [13], which is comparable to the MFs in the vicinity of transformers. These effects have not yet been evaluated, and the issue of these local gradient MFs and their rates of change has not yet been standardized.

Any change in the position of the end point of the rotating vector MF is caused by a change in the ambient parameters. They are the result of changes in the dynamics of bodies in the Earth's field and changes caused by local electrical devices in a particular space. The MF image can be used to compare between the recommended MF state and the actual state. The degree of difference defines the extent of the problem. There are existing noise maps and standards, and there should be MF maps for specific modes in EVs. There are also no recommended places in EVs where MFs should be measured during charging. The position of the rotating vector MF gives designers new tools for human protection in prevention already in the phase of EV construction. The issue of electromagnetic compatibility does not solve the issue of the influence of MFs on humans.

\section{Conclusions}

The ICNIRP standards define MF limit values for immediate consequences. They do not, however, evaluate long-term conditions. The limit values for MFs are defined for stable sources where EV charging stands belong. However, an EV is a mobile device. The effective $B_{R M S}$, value (Table 1), which is a scalar value, was chosen as a representative parameter in these standards for MFs. Experimental experiences and MF measurements in any location and independent direction offer a new view of indicated MFs. The rotating vector $B_{\text {total }}$ defined the space and the value of an MF, which was compared with the limit values. Such measurement allowed for identification of the space with the lowest and highest values of MFs in the selected area. As long as a DFT is performed, an MF's performance can be easily determined as a function of the induction, frequency, and time.

The investigated devices when charging electric vehicles (EVs) specifically were a 100-kVA transformer, 250-kVA $(22 \mathrm{kV} / 400 \mathrm{~V})$ transformer, cables of $600 \mathrm{~A}$, a fixed charging stand, and an AC/DC transformer in the EV induce magnetic fields with specific values. Dynamic sources, which were a fixed charging stand and an AC/DC transformer in the EV, had higher values (about $25 \mu \mathrm{T}$ at a frequency of $50 \mathrm{~Hz}$ ). At the same time, an increase in the frequency of 100,150,200,250, and $300 \mathrm{~Hz}$ for dynamic sources repeatedly induced a magnetic field, but a gradual decrease was monitored in the $B_{R M S}$ values. The obtained values prove the presence of magnetic fields, but with the development of mobility, it is necessary to continue to deal with this issue. Based on the results obtained from the measurements and analyses, it is necessary to focus on the following problems in the future:

- Development of a standard for comparison of emitted MP values for EV charging stands, as there are only standards for stable sources in general.

- Legally, the electric car cannot be considered a stable source. Therefore, it is also appropriate to specify the places in the EV where it is recommended to measure the MP. Such places include the converter, the driver's seat, and the EV passenger.

- The inconsistency of evaluation approaches and standards in the EU indicates the appropriateness of introducing dosimetry measurement. This measurement would make it possible to measure the processes taking place while driving the EV (e.g., during accelerations and recuperation when MPs are also produced, as pointed out in [57]).

Author Contributions: Conceptualization, M.O. and D.J.; methodology and software, M.O.; investigation and data curation, M.O. and D.J.; resources, I.M. and L.M.O.; writing—original draft 
preparation, M.O. and I.M.; writing-review and editing, M.O., I.M., L.M.O. and E.S.; project administration, E.S. All authors have read and agreed to the published version of the manuscript.

Funding: The article was prepared within project APVV-19-0367 Framework of the Integrated Approach to Process Security Management for Intelligent Enterprise, project KEGA 013TUKE-4/2020 Transfer of knowledge from research of means using augmented reality to the educational process in the field of security of technical systems and Žilina University Grant No 12716 Evaluation of fire-technical characteristics of natural and synthetic (including recycled) organic materials used in transport. Funder for all grands is The Ministry of Education, Science, Research and Sport of the Slovak Republic.

Institutional Review Board Statement: Not applicable.

Informed Consent Statement: Not applicable.

Acknowledgments: This article was supported by projects APVV-19-0367 and KEGA 013TUKE4/2020 and Grant No 12716 of Zilina University.

Conflicts of Interest: The founding sponsors had no role in the design of the study; in the collection, analyses, or interpretation of data; in the writing of the manuscript; or in the decision to publish the results.

$\begin{array}{ll}\text { Abbreviations } \\ B_{R M S} & \text { Root mean square of magnetic induction } \\ B_{\text {total }} & \text { Maximum value of the magnetic field rotating vector } \\ \text { DFT } & \text { Discrete fast Fourier transform } \\ \text { ELF } & \text { Extremely low frequency } \\ \text { EMFs } & \text { Electromagnetic fields } \\ \text { EV } & \text { Electric vehicle } \\ \text { ICNIRP } & \text { International Commission on Non-Ionizing Radiation Protection } \\ \text { MRI } & \text { Magnetic resonance imaging } \\ \text { MF } & \text { Magnetic field }\end{array}$

\section{References}

1. European Committee for Standardization. Standard ENV 20166/1995 Human Exposure to Electromagnetic Fields Low-Frequency; European Committee for Standardization: Brussels, Belgium, 1995.

2. International Commission on Non-Ionizing Radiation Protection (ICNIRP). Guidelines for Limiting Exposure to Time-Varying Electric, Magnetic, and Electromagnetic Fields (up to $300 \mathrm{GHz}$ ). Health Phys. 1998, 74, 494-522.

3. Bailey, W.H. Probabilistic approach to deriving risk-based exposure guidelines: Application to extremely low frequency magnetic fields. Radiat. Prot. Dosim. 1997, 72, 327-336. [CrossRef]

4. ICNIRP. Guidelines for Limiting Exposure to Electric Fields Induced by Movement of the Human body in a static magnetic field and by time-varying magnetic fields below $1 \mathrm{~Hz}$. Health Phys. 2010, 99, 818-836. [CrossRef] [PubMed]

5. ICNIRP. 2014 Guidelines for Limiting Exposure to Electric Fields Induced by Movement of the Human Body in a static magnetic fields and by time-varying magnetic fields below $1 \mathrm{~Hz}$. Health Phys. 2014, 106, 418-425. [CrossRef] [PubMed]

6. European Committee for Standardization. Directive 2013/35/EU on the Minimum Health and Safety Requirements Regarding the Exposure of Workers to the Risks Arising from Physical Agents (Electromagnetic Fields); European Committee for Standardization: Brussels, Belgium, 2013.

7. EU. Non-Binding Guide to Good Practice for Implementing Directive 2013/35/EU on Electromagnetic Fields Volume 1-Practical Guide; Publications Office of the European Union: Luxembourg; Brussels, Belgium, 2015. (In Slovak)

8. IEEE. Standard for Safety Levels with Respect to Human Exposure to Radio Frequency Electromagnetic Fields, $3 \mathrm{kHz}$ to $300 \mathrm{GHz}$; IEEE Std C951-2005 (Revision of IEEE Std C951-1991); IEEE: Piscataway, NJ, USA, 2006.

9. Standard of Building Biology Testing Methods, SBM-2015, Institutfür Baubiologie + Ökologie IBN. Available online: https: // buildingbiology.com/site/downloads/standard-2015-englisch.pdf (accessed on 11 May 2021).

10. Heilmaier, C.; Theysohn, J.M.; Maderwald, S.; Kraff, O.; Ladd, M.E.; Ladd, S.C. A large-scale study on subjective perception of discomfort during 7 and 1.5 T MRI examinations. Bioelectromagnetics 2011, 32, 610-619. [CrossRef] [PubMed]

11. Oravec, M.; Lipovsky, P.; Šmelko, M. Low Frequency Magnetic Fields in the Working Environment; Equilibria s.r.o.: Košice, Slovakia, $2020 ;$ p. 187.

12. van Nierop, L.E.; Slottje, P.; van Zandvoort, M.J.E.; de Vocht, F.; Kromhout, H. Effects of magnetic stray fields from a 7 tesla MRI scanner on neurocognition: A double-blind andomised crossover study. Occup. Environ. Med. 2012, 69, 759-766. [CrossRef] 
13. Oravec, M.; Draganova, K.; Lipovsky, P.; Witoš, M.; Šmelko, M. Low Frequency Magnetic Field—Instruments, Measurements, New Technologies; Equilibria s.r.o.: Košice, Slovakia, 2020; p. 187.

14. Oravec, M.; Vargová, S.; Glatz, J.; Ižaríková, G. Using Magnetometry for Identifying Objects. Sci. Popul. Prot. 2013, 1, 1-18. Available online: https:/ / www.actamechanica.sk/pdfs/ams/2013/02/06.pdf (accessed on 6 February 2013). (In Slovak).

15. Okokon, E.O.; Roivainen, P.; Kheifets, L.; Mezei, G.; Juutilainen, J. Indoor transformer stations and ELF magnetic field exposure: Use of transformer structural characteristics to improve exposure assessment. J. Expo. Sci. Environ. Epidemiol. 2014, $24,100-104$. [CrossRef]

16. Witos, M.; Szymanski, M.; Oravec, M.; Bogucki, K. Magnetic State Observer in NDT and SHM Studies. In Proceedings of the NDT in Progress 2019, 10th International Workshop of NDT Experts and Students, Prague, Czech Republic, 7-9 October 2019. Available online: https:/ / www.ndt.net/article/ndtp2019/papers/12.pdf (accessed on 12 October 2019).

17. Witos, M.; Zlieja, M.; Kurzyk, B. IT Support of NDE and SHM with application of the metal magnetic memory method. In Proceedings of the 7th International Symposium on NDT in Aerospace, Bremen, Germany, 16-17 October 2015; We.4.A.3. Available online: https: / / 2015.ndt-aerospace.com/Proceedings/We4A-IT-Developments-and-Solutions (accessed on 31 January 2021).

18. Pacaiova, H.; Oravec, M.; Šmelko, M.; Lipovsky, P.; Forraj, F. Extra low frequency magnetic fields of welding machines and personal safety. J. Electr. Eng. 2018, 69, 493-496. Available online: https://sciendo.com/abstract/journals/jee/69/6/article-p493 .xml (accessed on 12 October 2018).

19. European Standard Organisation. EN 50499: 2020-02 Procedure for the Assessment of the Exposure of Workers to Electromagnetic Fields; European Standard Organisation: Brussels, Belgium, 2020.

20. Trentadue, G.; Pinto, R.; Zanni, M.; Scholz, H. Konstantinos Pliakostathis 1 and Giorgio Martini 1 Low Frequency Magnetic Fields Emitted by High-Power Charging Systems. Energies 2020, 13, 1594. [CrossRef]

21. Oravec, M.; Šmelko, M. Magnetic fields of mobile sources. Safe Work 2019, 50, 35-39. (In Slovak)

22. Act No. 355/2007 Coll. Act on the Protection, Promotion and Development of Public Health and on Amendments to Certain Acts. Available online: https:/ / www.zakonypreludi.sk/zz/2007-355 (accessed on 31 July 2007). (In Slovak).

23. Regulation of the Government of the Slovak Republic 334/2020 Coll. On the Minimum Health and Safety Requirements for the Protection of Workers from the Risks Related to Exposure to Electromagnetic Fields. Available online: https: / www. zakonypreludi.sk/zz/2020-334 (accessed on 21 November 2020).

24. OOFŽP-7674/2010. Professional Guidance of the Ministry of Health of the Slovak Republic, which Regulates the Procedure for Objectifying the Physical Factors of the Environment and the Working Environment. Available online: https://www.epi.sk/ vestnik-mzsr/2011-1 (accessed on 4 February 2011).

25. Bulletin of the Ministry of Health Slovak Republic No. 36/2019 of Evaluating the Exposure of the Population to the Electromagnetic Field. Professional Guidance of the Ministry of Health of the Slovak Republic, Which Regulates the Procedure for Measuring the Exposure to Electromagnetic Waves, Bratislava, Slovak Republic, 2019. (In Slovak). Available online: https: / / www.epi.sk/vestnik-mzsr/2019-36 (accessed on 4 October 2019). (In Slovak).

26. Liptai, P.; Dolník, B.; Pavlík, M.; Zbojovský, J.; Špes, M. Check measurements of magnetic flux density: Equipment design and the determination of the confidence interval for EFA 300 measuring devices. Measurement 2017, 111, 51-59. [CrossRef]

27. Šmelko, M.; Draganova, K.; Lipovsky, P.; Semrád, K.; Blišt’anová, M.; Kašper, P. Non-Destructive Testing of Aircraft Structures Using Microwire-Based Tensile Stress Sensor. Appl. Sci. 2020, 10, 8218. [CrossRef]

28. Oravec, M.; Draganova, K.; Lipovsky, P.; Šmelko, M.; Bugár, T. UV 8860. Device for Slip Control by Identifying the Magnetic Field of Elements of an Asynchronous Motor with a Frequency Converter. Utility Model 8860. Available online: http:/ /wbr.indprop. gov.sk/WebRegistre/UzitkovyVzor/Detail/50040-2019 (accessed on 3 September 2020).

29. Oravec, M.; Šmelko, M.; Lipovsky, P.; Draganova, K.; Adamčík, P. UV 50084-2019. Device and Procedure for Identification of Errors of Rotary Electric Machines by Magnetic Field up to $250 \mathrm{~Hz}$. Available online: https:/ / wbr.indprop.gov.sk/WebRegistre/ UzitkovyVzor/Detail/50084-2019 (accessed on 2 December 2020).

30. Draganova, K.; Lassak, M.; Lipovsky, P.; Kan, V.; Kliment, T. Gradient methodology for 3-axis accelerometer static calibration. In Proceedings of the International Conference on Military Technologies (ICMT), Brno, Czech Republic, 19-21 May 2015; IEEE: Piscataway, NJ, USA, 2015; pp. 1-5.

31. Kliment, T.; Praslička, D.; Lipovsky, P.; Draganova, K.; Závodský, O. Calibration of Magnetometerfor Small Satellites Using Neural Network. Acta Phys. Pol. A 2017, 131, 1129-1131. [CrossRef]

32. Lipovsky, P.; Šmelko, M.; Fil'ko, M.; Draganova, K.; Blažek, J.; Hudák, J.; Andoga, R.; Szabo, S. Relax-Type Magnetometer with Direct Optocoupler Relaxation. Acta Phys. Pol. A 2020, 137, 681-683. [CrossRef]

33. Praslička, D.; Lipovský, P.; Hudák, J.; Šmelko, M. Estimation of multichannel magnetometer noise floor in ordinary laboratory conditions. Acta Phys. Pol. A 2017, 131, 1123-1125. [CrossRef]

34. Lipovsky, P.; Draganova, K.; Smelko, M.; Volcko, T. Vector magnetometer used as magnetometric security subsystem. In Proceedings of the International Conference on Military Technologies (ICMT) 2015, Brno, Czech Republic, 19-21 May 2015; IEEE: Piscataway, NJ, USA, 2015. Book Series. pp. 527-530.

35. Zhu, Y.; Du, A.; Luo, H.; Qiao, D.; Zhang, Y.; Ge, Y.; Yang, J.; Sun, S.; Zhao, L.; Ou, J.; et al. The Fluxgate Magnetometer of the Low Orbit Pearl Satellites (LOPS): Overview of in-flight performance and initial results. Geosci. Instrum. Method. Data Syst. 2021, 10, 227-243, Discussion started: 29 March 2021. [CrossRef] 
36. Liptai, M.; Moravec, E.; Lumnitzer, K.; Lukáčová, K. Impact analysis of the electromagnetic fields of transformer stations close to residential buildings. In Proceedings of the 14th International Multidisciplinary Scientific GeoConference SGEM, Albena, Bulgaria, 17-26 June 2014; STEF92 Technology Ltd.: Sofia, Bulgaria, 2014; Volume 1, pp. 355-360.

37. Bowman, J.D. Hazard surveillance for industrial magnetic fields: II. Field characteristics from waveform measurements. Ann. Occup. Hyg. 2000, 44, 615-633. [CrossRef]

38. Oravec, M.; Lipovský, P.; Šmelko, M.; Adamčík, P.; Witoś, M.; Kwaśniewski, J. Low-Frequency Magnetic Fields in Diagnostics of Low-Speed Electrical and Mechanical Systems. Sustainability 2021, 13, 9197. [CrossRef]

39. Chadwick, P.; Lowes, F. Magnetic fields on British trains. Ann. Occup. Hyg. 1998, 42, 331-335. [CrossRef]

40. AGNIR-Advisory Group on Non-Ionising Radiation. ELF Electromagnetic Fields and the Risk of Cancer; National Radiological Protection Board: Chilton, UK, 2001; Documents of the NRPB, Volume 2, No.1.

41. Electric and Magnetic Fields and Health. Available online: http://www.emfs.info/sources/underground/ (accessed on 7 April 2021).

42. Swanson, J.; Tripp, H. Electric and Magnetic Fields Report. Document 8.25; North Wales Connection Project; National Grid: Warwick, UK, September 2018; p. 51.

43. Jelínek, L. Magnetická pole v Okolí Vodičů Protékaný Chelektrickým Proudem s Frekvencí 50 Hz. InformaceNRLl č. 12/2002. Available online: http:/ / www.szu.cz/uploads/documents/cpl/NRL_Eletromag/NRL_12.pdf (accessed on 9 May 2021).

44. Leszczynski, D. Rapporteur report: Cellular, animal and epidemiological studies of the effects of static magnetic fields relevant to human health. Prog. Biophys. Mol. Biol. 2005, 87, 247-253. [CrossRef]

45. Feychting, M. Health effects of static magnetic fields-a review of the epidemiological evidence. Prog. Biophys. Mol. Biol. 2005, 87, 241-246. [CrossRef]

46. Halgamuge, M.N.; McLean, L. Measurement and analysis of power-frequency magnetic fields in residences: Results from a pilot study. Measurement 2018, 125, 415-424. [CrossRef]

47. Pasqual, E.; Boussin, F.; Bazyka, D.; Nordenskjold, A.; Yamada, M.; Ozasa, K.; Pazzaglia, S.; Roy, L.; Thierry-Chef, I.; de Vathaire, F.; et al. Cognitive effects of low dose of ionizing radiation-Lessons learned and research gaps from epidemiological and biological studies. Environ. Int. 2021, 147, 106295. [CrossRef]

48. Oravec, M.; Pacaiova, H.; Ižaríková, G.; Hovanec, M. Magnetic Field Image-Source of Information for Action Causality Description. In Proceedings of the 2019 IEEE 17th World Symposium on Applied Machine Intelligence and Informatics (SAMI), Herl'any, Slovakia, 24-26 January 2019.

49. Gajšek, P.; Ravazzani, P.; Grellier, J.; Samaras, T.; Bakos, J.; Thuróczy, G. Review of Studies Concerning Electromagnetic Field (EMF) Exposure Assessment in Europe: Low Frequency Fields (50 Hz-100 kHz). Int. J. Environ. Res. Public Health 2016, 13, 875. [CrossRef] [PubMed]

50. Röösli, M.; Jenni, D.; Kheifets, L.; Mezei, G. Extremely low frequency magnetic field measurements in buildings with transformer stations in Switzerland. Sci. Total. Environ. 2011, 409, 3364-3369. [CrossRef] [PubMed]

51. Abuasbi, F.; Lahham, A.; Abdel-Raziq, I.R. Residental exposure to extremely low frequency electric and magnetic fields in the city of Ramallah-Palestine. Radiat. Prot. Dosim. 2018, 179, 49-57. [CrossRef] [PubMed]

52. Khan, M.W.; Roivainen, P.; Ferrala, M.; Tiikkaja, M.; Sallmén, M.; Hietanen, M.; Juutilainen, J. A pilot study on the reproductive risks of maternal exposure to magnetic fields from electronic article surveillance systems. Int. J. Radiat. Biol. 2018, 94, 902-908. [CrossRef]

53. Dorokhov, V.B.; Taranov, A.I.; Narbut, A.M.; Sakharov, D.S.; Gruzdeva, S.S.; Tkachenko, O.N.; Arsen'ev, G.N.; Blochin, I.S.; Putilov, A.A. Effects of Exposure to a Weak Extremely Low Frequency Electromagnetic Field on Daytime Sleep Architecture and Length. Sleep Med. Res. 2019, 10, 97-102. [CrossRef]

54. Ilonen, K.; Markkanen, A.; Mezei, G.; Juutilainen, J. Indoor transformer stations as predictors of residential ELF magnetic field exposure. Bio. Electro. Magnetic. 2008, 29, 213-218. [CrossRef] [PubMed]

55. Navarro-Camba, E.A.; Segura-García, J.; Gomez-Perretta, C. Exposure to $50 \mathrm{~Hz}$ Magnetic Fields in Homes and Areas Surrounding Urban Transformer Stations in Silla (Spain): Environmental Impact Assessment. Sustainability 2018, 10, 2641. [CrossRef]

56. Annual Report of the National Reference Centers Established on the Basis of Public Health Office Slovak Republic in 2019. Available online: https://www.uvzsr.sk/docs/vs/Vyrocna_sprava_NRC_2019.pdf (accessed on 1 March 2019).

57. Šmelko, M.; Lipovský, P.; Draganová, K.; Ň́k, J.; Novot, J.; Oravec, M.; Šolc, M.; Andoga, R.; Rozenberg, R. Low Frequency Magnetic Fields and Safety. Acta Phys. Pol. A 2020, 137, 693-696. [CrossRef] 